\title{
Aggression and Conduct Disorder in Young Children. A Case Report
}

\author{
Hadia Crider, Kunal Malhotra, Garima Singh \\ University of Missouri Hospital and Clinics, Columbia, USA \\ Email: singhga@health.missouri.edu
}

How to cite this paper: Crider, H., Malhotra, K. and Singh, G. (2018) Aggression and Conduct Disorder in Young Children. A Case Report. Journal of Biosciences and Medicines, 6, 57-61.

https://doi.org/10.4236/jbm.2018.62005

Received: January 9, 2018

Accepted: February 24, 2018

Published: February 27, 2018

Copyright ( $) 2018$ by authors and Scientific Research Publishing Inc. This work is licensed under the Creative Commons Attribution International License (CC BY 4.0).

http://creativecommons.org/licenses/by/4.0/

(c) (i) Open Access

\begin{abstract}
Childhood Onset Conduct Disorder [CD] is a condition characterized by at least one symptom of conduct disorder (based on Diagnostic and Statistical Manual of Mental Disorders criteria-Fifth Edition) prior to 10 years of age. Children affected exhibit disruptive behaviors, usually negative, hostile, and defiant behavior similar to Oppositional Defiant Disorder [ODD]. As the child gets older they begin to display more characteristic of Conduct Disorder (lying, fighting, and stealing, vindictive behavior). These children are also likely to have comorbidities including Attention Deficit Hyperactivity Disorder (ADHD), learning disabilities, poor academic achievement, and substance abuse. Distinguishing early between symptoms of Conduct Disorder versus other differential diagnoses is essential in effective treatment. Early intervention with these children leads to a better prognosis and likelihood of functioning in society. This case illustrates the difficulty of diagnosing a young child with Childhood Onset Conduct Disorder.
\end{abstract}

\section{Keywords \\ CD, Conduct Disorder, Aggression, Young Children}

\section{Introduction}

This case illustrates the complexity of this diagnosis in a young child. He is a victim of neglect and presents with suggestive symptoms of Childhood Onset Conduct Disorder. He has no prior psychiatric history. He was diagnosed with ADHD and Disinhibited Social Engagement Disorder after initial psychiatric assessment. His medical history is unremarkable. Patient was born vaginally at 40 weeks with no complications at birth; however he was exposed to methamphetamine in utero. His developmental milestones were significantly delayed in communication, motor, and social skills. He lived with biological mother from 
birth until age 2. During this time he suffered from neglect and malnutrition. His biological mother was not living in a stable home and would stay with friends. She was using illicit substances during this time period. Children's services removed him from mother's custody and he was placed with biological father and stepmother. He does not have current contact with biological mother.

\section{Demography}

Patient is a 5 year old male from Missouri. He lives with father, stepmother, 2 -year old brother, and 13 year old cousin. He is in Kindergarten.

\section{Mode of Referral}

He was seen for an initial psychiatric evaluation at the Outpatient Clinic for Autism Spectrum Disorder and Developmental Disorder and then a month later was admitted at an inpatient psychiatric facility after family brought him to the emergency room for safety concerns.

\section{Case Presentation}

A 5 year old male with no past psychiatric history was seen for the first time at the Outpatient Clinic for Autism Disorder and Developmental Disorder for impulsive and violent behavior since age 2 . History was provided mostly from parents (father and stepmother) during the initial assessment. According to his parents he was having issues with impulse control, short attention span, and hyperactivity. His behavioral issues were extreme and difficult to redirect. $\mathrm{He}$ would become upset with little or no triggers and then proceed to kick, scream, urinate, and defecate in the living room and smear feces on the wall. He would attempt to hurt his 9 month old baby brother multiple times. Parents were reported to Child Protective Services because he gave baby brother a black eye by hitting him with a sock filled with nuts and bolts. He was violent towards animals and snapped the necks of multiple animals ( 9 cats, 4 rabbits, 1 turkey, 3 baby hawks, multiple dogs and pigs) and per parents was not remorseful about his actions. During interview he admitted to hitting a pig in the eye with a hammer because he thought it was funny. His behavioral problems and outbursts were also occurring at school. He starts fights with the other kids by kicking, biting, and punching them. He lies to get out of trouble. He steals things from the other kids at school. He plays aggressively with toys and breaks them, throws them, and stomps on them. He is sensitive to loud noises. He has difficulty using a fork and spoon. He self-reported his mood to be happy. He denies any mania symptoms. He denies any issues with anxiety. He denies any psychotic symptoms. He reports having inattentive and hyperactive symptoms of ADHD which was attested by parents and teachers report. After his initial appointment he was referred for neuropsychological testing to screen for Autism Spectrum Disorder. He was started on medications, Guanfacine $0.5 \mathrm{mg}$ qam, qnoon to manage impulsive behaviors. He was given a diagnosis of Disinhibited Social Engagement 
Disorder, ADHD, and r/o Conduct Disorder. A month later he was admitted to an inpatient psychiatric hospital after family brought him to the emergency room due to him making homicidal threats towards family members. He grabbed a knife and held it up to his 13 year old cousin, threatening to kill her because she wouldn't let him watch TV. Patient also continued to see aggressive behaviors towards peers at school and animals. At home stepmother increased his dosage of Guanfacine to $1 \mathrm{mg}$ BID without any improvement in behaviors. Patient remained on the inpatient unit for a week. During this time he was tapered off Guanfacine and started on Amphetamine 2.5 qam for ADHD symptoms and Clonidine $0.05 \mathrm{mg}$ qhs to help with sleep. Medications were later titrated to Amphetamine $5 \mathrm{mg}$ in morning and Clonidine $0.1 \mathrm{mg}$ at bedtime. While he was on the inpatient unit it was determined that his violent tendencies were likely due to a lack of supervision. This determination was made from collateral information provided by his social worker. The diagnosis of r/o conduct disorder was removed from his diagnosis list and intensive home and community services were initiated. The neuropsychological testing showed he did not meet criteria for Autism Spectrum Disorder. He was continued on medications for ADHD and impulsivity (Amphetamine $5 \mathrm{mg}$ in morning and clonidine 0.1 $\mathrm{mg}$ at bedtime) and is participating in intensive family intervention services.

\section{Discussion}

It is a challenge when diagnosing a young child with Childhood Onset Conduct Disorder. Children find it difficult to verbalize their feelings. Their symptoms can have different meanings based on their developmental levels. In order to diagnose Childhood Onset Conduct Disorder individuals show at least one symptom characteristic of conduct disorder prior to 10 years of age [1]. In Childhood Onset Conduct Disorder, a combination of biological and psychosocial factors appears to contribute to the disorder. Children with Childhood Onset Conduct Disorder tend to be mostly male. The incidence of $\mathrm{CD}$ is not related to socioeconomic class or ethnic group. However research has shown children with Childhood Onset Conduct Disorder do have the following social factors: poverty, lower socioeconomic status, poor education, increased criminality in parents, substance use in parents, decreased community support, poor school achievement or poor family structure [2] [3]. These children tend to be more aggressive than the adolescent-onset youth. By age 18, the majority of youth with Childhood Onset Conduct Disorder meets the criteria for antisocial personality disorders and often end up incarcerated. The prevalence of Conduct Disorder is estimated between $2 \%$ and $8 \%$ of the general child and adolescent population. The prevalence of Childhood Onset Conduct Disorder is 3\% to $5 \%$ of youth with Conduct Disorder [4]. These children display disruptive behaviors early in childhood, usually as negative, hostile, and defiant behavior similar to oppositional defiant disorder. As the child grows, there is an escalation to behaviors more characteristic of Conduct Disorder (lying, fighting, and stealing, vindictive 
behavior). These children are also likely to have ADHD, learning disabilities, and poor academic achievement. A consistent finding is that children with ADHD are likely to have persistent conduct problems that extend into adulthood [2]. The association between ADHD and Conduct Disorder is especially strong for boys, although girls show a higher risk than boys to develop Conduct Disorder if they have ADHD [2] [5]. The addition of substance abuse to ADHD and Conduct Disorder is predictive of violent behavior for boys. Early treatment for ADHD, ODD and substance abuse is important in the treatment of Conduct Disorder. Children with Conduct Disorder also may show other forms of neuropsychiatric and neurobiological differences, such as low CSF serotonin levels and abnormal dopamine B-hydroxylase (DBH), reduction of grey matter in the amygdala which might indicate a reduction in fear conditioning [6]. As these children grow they have a higher risk of substance abuse, erratic employment and physical abuse of their partners and children. There is also a high rate of symptom overlap of Conduct Disorder with other differential psychiatric diagnoses. Children can have irritable and impulsive/dangerous behaviors associated with ADHD, Anxiety, depression, substance use, learning disorders, mania, fetal alcohol syndrome, abuse victims, Reactive Attachment Disorder [RAD] [2]. Some of these disorders can also be comorbid (ADHD, depression, anxiety, substance use, and learning disorder) which makes it difficult to make an accurate diagnosis of Childhood Onset Conduct Disorder. Childhood Onset Conduct Disorder requires early intervention and long term follow-up. These children benefit from multiple sessions of therapy for longer periods of time. There is no pharmacological intervention to treat Conduct Disorder however comorbid issues need to be addressed (anxiety, depression, ADHD, substance use) [4]. Conduct Disorder children benefit from Cognitive Behavioral Therapy [CBT] (particularly problem solving skills training (PSST), family intervention (parent training for consistent behavior interventions), school intervention (appropriate academic interventions and social engagement with peers), and working with a juvenile officer. Patients may also benefit from long term residential treatment facilities if behaviors continue to be extreme [4]. Antipsychotics are used to manage aggressive behaviors [7].

\section{Conclusion}

Childhood Onset Conduct Disorder can be difficult to diagnose due to comorbidities, symptoms presentation as well biopsychosocial factors as in the case presented. It was determined that his behaviors were due to a lack of supervision in the home versus a diagnosis of Childhood Onset Conduct Disorder. The early recognition and interventional treatment of Childhood Onset Conduct Disorder can prevent legal issues and future incarceration. Treatment includes treating comorbidities, CBT, Family and school intervention/psychoeducation modifies behaviors. Antipsychotics may be used to manage aggressive behaviors. In the patient's case he is being treated for ADHD. His parents are using behavioral 
techniques with him to help modify his behaviors. Since implementing these techniques and using ADHD medication his behavior continues to improve. $\mathrm{He}$ is not as impulsive as previously and will think through his decisions. He is recognizing his behavior has consequences and will be punished if he doesn't follow the rules set by father and stepmother. He will ask permission to do things instead of just doing what he wants. He is not running away from home or school. He has not had any additional instances of animal cruelty. His current management (treating ADHD, CBT, and family intervention) has improved his prognosis.

\section{References}

[1] American Psychiatric Association (2013) Diagnostic and Statistical Manual of Mental Disorders. Fifth Edition. American Psychiatric Association, Arlington.

[2] Loeber, R. and Keenan, K. (1994) Interaction between Conduct Disorder and Its Comorbid Conditions: Effects of Age and Gender. Clinical Psychology Review, 14, 497-523. https://doi.org/10.1016/0272-7358(94)90015-9

[3] American Academy of Child and Adolescent Psychiatry (1997) Practice Parameters for the Assessment and Treatment of Children, Adolescents, with Conduct Disorder. Journal of the American Academy of Child and Adolescent Psychiatry, 36, 122S-139S. https://doi.org/10.1097/00004583-199710001-00008

[4] Stephen, S. (2017) IACAPAP Textbook of Child and Adolescent Mental Health Conduct Disorder. ICAPAP, 26.

[5] Mannuzza, S., Klein, R., Konig, P. and Giampino, T. (1990) Childhood Predictors of Psychiatric Status in the Young Adulthood of Hyperactive Boys: A Study Control-ling for Chance Association. In: Robins, L. and Rutter, M., Eds., Straight and Devious Pathways from Childhood to Adulthood, Cambridge University Press, Cambridge.

[6] Lavin, M. and Rifkin, A. (1993) Diagnosis and Pharmacotherapy of Conduct Disorder. Progress in Neuro-Psychopharmacology \& Biological Psychiatry, 17, 875-885. https://doi.org/10.1016/0278-5846(93)90017-M

[7] Kazdin, A. (1989) Hospitalization of Antisocial Children: Clinical Course, Follow-Up Status, and Predictors of Outcome. Advances in Behaviour Research and Therapy, 11, 1-67. https://doi.org/10.1016/0146-6402(89)90025-8 